\title{
Impact of Relative Dose Intensity of Early-phase Lenvatinib Treatment on Therapeutic Response in Hepatocellular Carcinoma
}

\author{
AYA TAKAHASHI ${ }^{1}$, MICHIHISA MORIGUCHI ${ }^{1}$, YUYA SEKO ${ }^{1}$, HIROKI ISHIKAWA ${ }^{2}$, TAKAHARU YO ${ }^{2}$, \\ HIROYUKI KIMURA ${ }^{3}$, HIDEKI FUJII ${ }^{3}$, TOSHIHIDE SHIMA ${ }^{4}$, YASUHIDE MITSUMOTO ${ }^{4}$, HIROSHI ISHIBA ${ }^{5}$, \\ HIDETAKA TAKASHIMA ${ }^{6}$, YASUYUKI NAGAO ${ }^{7}$, MASAYASU JO $^{8}$, MASAHIRO ARAI $^{9}$, TASUKU HARA ${ }^{10}$, \\ AKIRA OKAJIMA ${ }^{11}$, AKIRA MURAMATSU ${ }^{12}$, ATSUHIRO MORITA ${ }^{13}$, NAOMI YOSHINAMI ${ }^{14}$, \\ TOMOKI NAKAJIMA ${ }^{15}$, HIRONORI MITSUYOSHI ${ }^{16}$, ATSUSHI UMEMURA ${ }^{1}$, \\ TAICHIRO NISHIKAWA ${ }^{1}$, KANJI YAMAGUCHI $^{1}$ and YOSHITO ITOH $^{1}$ \\ ${ }^{I}$ Department of Gastroenterology and Hepatology, Kyoto Prefectural University of Medicine, Kyoto, Japan; \\ ${ }^{2}$ Department of Gastroenterology and Hepatology, Omihachiman Community Medical Center, Shiga, Japan; \\ ${ }^{3}$ Department of Gastroenterology, Japanese Red Cross Kyoto Daiichi Hospital, Kyoto, Japan; \\ ${ }^{4}$ Department of Gastroenterology and Hepatology, Saiseikai Suita Hospital, Osaka, Japan; \\ ${ }^{5}$ Department of Gastroenterology and Hepatology, \\ North Medical Center of Kyoto Prefectural University of Medicine, Kyoto, Japan; \\ ${ }^{6}$ Department of Gastroenterology, Osaka General Hospital of West Japan Railway Company, Osaka, Japan; \\ ${ }^{7}$ Department of Gastroenterology, Matsushita Memorial Hospital, Osaka, Japan; \\ ${ }^{8}$ Department of Gastroenterology, Otsu City Hospital, Shiga, Japan; \\ ${ }^{9}$ Department of Gastroenterology, Kyoto Yamashiro General Medical Center, Kyoto, Japan; \\ ${ }^{10}$ Department of Gastroenterology, Fukuchiyama City Hospital, Kyoto, Japan; \\ ${ }^{11}$ Department of Gastroenterology, Koseikai Takeda Hospital, Kyoto, Japan; \\ ${ }^{12}$ Department of Gastroenterology, Akashi City Hospital, Hyogo, Japan; \\ ${ }^{13}$ Department of Gastroenterology, Japanese Red Cross Kyoto Daini Hospital, Kyoto, Japan; \\ ${ }^{14}$ Department of Gastroenterology, Kyoto City Hospital, Kyoto, Japan; \\ ${ }^{15}$ Department of Gastroenterology, Saiseikai Kyoto Hospital, Kyoto, Japan; \\ ${ }^{16}$ Department of Gastroenterology and Hepatology, Kyoto Chubu Medical Center, Kyoto, Japan
}

\begin{abstract}
Background: Factors associated with response to lenvatinib have not been clarified in patients with hepatocellular carcinoma (HCC). Patients and Methods: This study retrospectively analyzed 50 patients treated with lenvatinib as first-line therapy between March 2018 and March 2019. Patients were divided into two groups by the Modified Response Evaluation Criteria in Solid Tumours (mRECIST) (responders and non-responders, whose best
\end{abstract}

Correspondence to: Dr. Michihisa Moriguchi, Department of Gastroenterology and Hepatology, Kyoto Prefectural University of Medicine, 465 Kajii-cho, Kawaramachi-Hirokoji, Kamigyo-ku, Kyoto 602-8566, Japan. Tel: +81 752515519, Fax: +81752510710 , e-mail: mmori@koto.kpu-m.ac.jp

Key Words: Hepatocellular carcinoma, lenvatinib, dose intensity, objective response. overall responses were complete $(C R) /$ partial response $(P R)$ and stable (SD)/progressive disease (PD), respectively). Factors associated with response were assessed, including the relative dose intensity 8 weeks after lenvatinib induction $(8 \mathrm{~W}$ RDI). Results: The best overall responses were 0/22/14/14 of $C R / P R / S D / P D$. Multivariate analysis revealed that only $8 \mathrm{~W}$ $R D I$ was significantly associated with response. The receiver operating characteristic curve for $8 W-R D I$ in differentiating responders from non-responders revealed a cut-off value of $75 \%$. Patients with $8 W-R D I \geq 75 \%$ experienced a higher response rate and longer progression-free survival than patients with $8 W-R D I<75 \%$. Conclusion: Our results suggest that maintaining an RDI $\geq 75 \%$ during the initial 8 weeks of lenvatinib treatment has a favorable impact on response.

Hepatocellular carcinoma (HCC) is the fifth most common malignancy worldwide and the second leading cause of cancer-related death, resulting in more than 700,000 deaths 
Table I. Patient characteristics.

\begin{tabular}{|c|c|c|c|c|c|}
\hline Variable & & Total $(n=50)$ & Responders ( $\mathrm{n}=22$ ) & Non-responders $(\mathrm{n}=28)$ & $p$-Value \\
\hline Age, years & Median (range) & $78(53-93)$ & $70(53-86)$ & $79(57-93)$ & 0.075 \\
\hline Gender, $\mathrm{n}$ & Male/female & $38 / 12$ & $19 / 3$ & $19 / 9$ & 0.186 \\
\hline ECOG PS, n & $0 / 1 / 2$ & $37 / 12 / 1$ & $17 / 5 / 0$ & $20 / 7 / 1$ & 0.648 \\
\hline Body weight, $\mathrm{n}$ & $<60 / \geq 60 \mathrm{~kg}$ & $33 / 17$ & $13 / 9$ & $20 / 8$ & 0.386 \\
\hline Etiology, $\mathrm{n}$ & HBV/HCV/alcohol/other & $9 / 18 / 8 / 15$ & $5 / 8 / 3 / 6$ & $4 / 10 / 5 / 9$ & 0.868 \\
\hline Child-Pugh score, $\mathrm{n}$ & $5 / 6 / 7$ & $30 / 17 / 3$ & $17 / 5 / 0$ & $13 / 12 / 3$ & 0.056 \\
\hline ALBI grade, $\mathrm{n}$ & $1 / 2$ & $18 / 32$ & $9 / 13$ & $8 / 20$ & 0.386 \\
\hline EHS, n & Yes/no & $13 / 37$ & $9 / 13$ & $4 / 24$ & 0.051 \\
\hline MVI, n & Yes/no & $8 / 42$ & $3 / 19$ & $5 / 23$ & 0.715 \\
\hline $\mathrm{AFP}, \mathrm{ng} / \mathrm{ml}$ & Median (range) & $90.1(2.1-185,772)$ & $24.5(2.8-25,881)$ & $384(2.1-185,772)$ & 0.097 \\
\hline PIVKA II, mAU/ml & Median (range) & $540.5(11.0-316,000)$ & $164.5(24-14,161)$ & $868(11-316,000)$ & 0.051 \\
\hline Prior TACE history, $n$ & Yes/no & $38 / 12$ & $17 / 5$ & $21 / 7$ & $>0.99$ \\
\hline Initial dose of LEN, $n$ & Full/reduced & $45 / 5$ & $21 / 1$ & $23 / 4$ & 0.362 \\
\hline $8 \mathrm{~W}-\mathrm{RDI}, \%$ & Median (range) & $74(8-100)$ & $100(42.4-100)$ & $48.2(8-100)$ & $<0.001$ \\
\hline
\end{tabular}

ECOG: Eastern Cooperative Oncology Group; PS: performance status; HBV: hepatitis B virus; HCV: hepatitis C virus; ALBI: Albumin-Bilirubin; EHS: extrahepatic spread; MVI: macrovascular invasion; AFP: alpha-fetoprotein; PIVKA-II: protein induced by vitamin K absence or antagonistII; TACE: transarterial chemoembolization; LEN: lenvatinib; $8 \mathrm{~W}-\mathrm{RDI}$ : relative dose intensity 8 weeks after lenvatinib induction. Bold font for indicates p-values of less than 0.1 , for factors which were subsequently included in the multivariate analysis.

annually $(1,2)$. Only $40 \%$ of patients with HCC are diagnosed with early-stage disease, and even after successful early treatment, most patients experience disease recurrence; thus, almost half of all patients ultimately receive systemic therapies $(3,4)$.

Lenvatinib is an oral multi-target tyrosine kinase inhibitor (TKI) that has anti-angiogenic and antiproliferative effects. In the phase III REFLECT trial, lenvatinib was found to be non-inferior to sorafenib in terms of overall survival (OS) in patients with advanced HCC and has become available as a therapy in first-line setting for unresectable HCC (5). The response rate to lenvatinib according to the Modified Response Evaluation Criteria in Solid Tumours (mRECIST) (6) was significantly higher than that for sorafenib $(40.6 \%$ vs. $12.4 \%$, respectively). More recently, a post-hoc analysis of the REFLECT trial reported that objective response (OR) by mRECIST was an independent predictor of OS and the median OS was 22.4 months for responders and 11.4 months for non-responders (7). The correlation between OR by mRECIST and OS has also been demonstrated for other targeted therapies (e.g. brivanib, nintedanib, and sorafenib) based on data from prospective randomized trials on HCC (8-10). Furthermore, if these drugs are effective, a greater choice of additional therapies, such as conversion hepatectomy, become available $(11,12)$. According to these reports and the high response rate to lenvatinib, the purpose of systemic chemotherapy in unresectable $\mathrm{HCC}$ is changing from controlling disease to yielding favorable responses. Therefore, in order to identify factors associated with OR to lenvatinib therapy is becoming increasingly crucial.
The relative dose intensity (RDI) is the ratio of the actual dose intensity of chemotherapy delivered to the standard recommended dose intensity (13). Several studies have demonstrated a correlation between RDI, particularly in the early phase of treatment, and survival in patients with various malignancies, such as renal cell carcinoma, gastrointestinal stromal tumor, soft-tissue sarcoma, and chronic myeloid leukemia treated with TKIs (14-17). However, to our knowledge, no studies have investigated the association between RDI and therapeutic efficacy in patients with HCC treated with TKIs. Indeed, patients receiving lenvatinib therapy, particularly in real-world settings, often undergo dose modifications due to several factors, including adverse events (AEs), reduced liver function, and deterioration of Eastern Cooperative Oncology Group performance status (ECOG PS) $(18,19)$. Thus, the doseresponse relationship is of critical concern. The aim of this study was to evaluate the impact of RDI during the early phase of lenvatinib treatment on therapeutic response in patients with HCC.

\section{Patients and Methods}

Study design and patients. This was an observational, retrospective, multicenter study focused on patients with HCC treated with lenvatinib in routine clinical practice. From March 2018 to March 2019 , lenvatinib was administered to 105 Japanese patients at 16 institutions in Japan [Kyoto Prefectural University of Medicine $(n=26)$, Omihachiman Community Medical Center $(n=14)$, Japanese Red Cross Kyoto Daiichi Hospital $(n=12)$, Saiseikai Suita Hospital $(n=11)$, North Medical Center of Kyoto Prefectural University of Medicine $(n=10)$, Osaka General Hospital of West Japan Railway 
Company ( $n=8)$, Matsushita Memorial Hospital $(n=4)$, Otsu City Hospital ( $n=4)$, Kyoto Yamashiro General Medical Center $(n=3)$, Fukuchiyama City Hospital ( $n=3)$, Koseikai Takeda Hospital $(n=2)$, Akashi City Hospital $(n=2)$, Japanese Red Cross Kyoto Daini Hospital ( $n=2)$, Kyoto City Hospital $(n=2)$, Saiseikai Kyoto Hospital $(\mathrm{n}=1)$, and Kyoto Chubu Medical Center $(\mathrm{n}=1)]$. Of these patients, 69 were given lenvatinib as first-line systemic treatment. Of these, after patients with a short observation period $(<8$ weeks) or those with lacking data were excluded, 50 patients were enrolled in the present study. They were divided into two groups, responders $(n=22)$ and non-responders $(n=28)$, based on whether their best overall responses were complete (CR)/partial (PR) response or stable (SD)/progressive (PD) disease, respectively. Data were obtained from clinical medical records with a cut-off date of March 31,2019 . This study was conducted in accordance with the Declaration of Helsinki. This study protocol was approved by the institution's Human Research Committees.

Diagnosis and treatment. The diagnosis of HCC was based on imaging results (20) and elevated serum level of alpha-fetoprotein (AFP) or protein induced by vitamin $\mathrm{K}$ absence or antagonist-II (PIVKA-II). Patients received oral lenvatinib at $12 \mathrm{mg} /$ day (for body weight $\geq 60 \mathrm{~kg}$ ) or $8 \mathrm{mg} /$ day (for body weight $<60 \mathrm{~kg}$ ), although lower starting doses were used in some cases based on physician judgement. Treatment was continued until tumor progression occurred or AEs impeding continuation developed. Dose modification due to AEs was allowed based on the treating physician's discretion. AEs were graded using the National Cancer Institute Common Terminology Criteria for Adverse Events (ver. 4.0) (21) and AEs resulting in treatment withdrawal, dose reduction, or drug interruption were defined as dose-limiting toxicities (DLTs). Radiological assessments using enhanced computed tomography or magnetic resonance imaging were performed at baseline and every 8 weeks thereafter by two hepatic physicians in our institutions (A.T and M.M.) in accordance with the mRECIST guidelines. A 'best overall response' was defined as the best response across all time points until PD during lenvatinib treatment.

Relative dose intensity. In order to investigate the impact of RDI during the early phase of treatment on the therapeutic efficacy of lenvatinib, we defined the initial 8-week RDI (8W-RDI) as early-phase dose intensity, consistent with the first evaluation period after initiation of lenvatinib therapy. 8W-RDI was defined as the ratio of the actual dose delivered during the initial 8 weeks to the standard dose (body weight $\geq 60 \mathrm{~kg}$ : $12 \mathrm{mg} \times 8$ weeks; $<60 \mathrm{~kg}: 8 \mathrm{mg} \times 8$ weeks).

Statistical analysis. In order to clarify factors contributing to response, different clinical parameters were assessed, including age, gender, ECOG PS, body weight, Child-Pugh score, albuminbilirubin (ALBI) grade (22), etiology, extrahepatic spread (EHS), macrovascular invasion, AFP, PIVKA-II, prior transarterial chemoembolization history, starting lenvatinib dose (full dose/reduced dose), and 8W-RDI. Univariate analyses were performed using Fisher's exact test and Mann-Whitney $U$-test, as appropriate. Multivariate analysis was performed by logistic regression analysis. The results were presented as odds ratio with $95 \%$ confidence intervals (CIs). A $p$-value of less than 0.05 was considered statistically significant. $8 \mathrm{~W}$-RDI cut-off values for predicting differences between responders and non-responders were calculated to produce receiver operating characteristic (ROC)
Table II. Multivariate analyses of factors contributing to objective response to lenvatinib in patients with hepatocellular carcinoma.

\begin{tabular}{lccc}
\hline & \multicolumn{3}{c}{ Multivariate analysis $\dagger$} \\
\cline { 2 - 4 } Factor & Odds ratio & $95 \%$ CI & $p$-Value \\
\hline Age, per 1 year increment & 0.923 & $0.832-1.024$ & 0.132 \\
Child-Pugh score, $<6$ & 1.523 & $0.305-7.601$ & 0.608 \\
EHS, absence & 1.078 & $0.182-6.384$ & 0.934 \\
AFP, <90 ng/mL & 3.061 & $0.564-16.598$ & 0.195 \\
PIVKA-II, <540 mAU/mL & 2.963 & $0.686-12.794$ & 0.146 \\
8W-RDI, per 1\% increment & 1.036 & $1.001-1.072$ & $\mathbf{0 . 0 4 1}$ \\
\hline
\end{tabular}

AFP: Alpha-fetoprotein; CI: confidence interval; EHS: extrahepatic spread; PIVKA-II: protein induced by vitamin $\mathrm{K}$ absence or antagonistII. †Estimated using logistic regression analysis. Bold font indicates significant $p$-values.

curves. Progression-free survival (PFS) was estimated using the Kaplan-Meier method, comparing high with low 8W-RDI by logrank test. Time to response was defined as the time from the initiation of lenvatinib to the date of OR achievement among responders. Statistical analyses were conducted using SPSS software Ver 25 (IBM, Armonk, NY, USA).

\section{Results}

Patient characteristics. The clinical profiles of the 50 study patients are summarized in Table I. Eleven deaths occurred during the observational period. The median follow-up period was 6.6 months; PFS was 5.8 months, time to treatment failure was 4.4 months, and median OS was not reached. The best overall response was PR in 22 patients (responders; no patient had CR) and SD and PD in 14 patients each, respectively (non-responders), giving an overall response rate of $44 \%$ and a disease control rate of $72 \%$. Among responders, 21 out of 22 patients $(95.5 \%)$ demonstrated PR at first evaluation after starting lenvatinib, and the median time to response was 7.8 weeks.

Factors associated with OR. Univariate analysis indicated that the median $8 \mathrm{~W}$-RDI in responders was significantly higher than that in non-responders $(p<0.001$; Table I). Age, Child-Pugh score, EHS, AFP, PIVKA-II, and 8W-RDI were entered into multivariate analysis. Multivariate logistic regression analyses revealed that $8 \mathrm{~W}$-RDI was the only independent factor predictive of response (odds ratio $=1.036$, 95\% CI=1.001-1.072; $p=0.041$; Table II).

Optimal cut-off value of RDI. An $8 \mathrm{~W}$-RDI of $75 \%$ was determined to be the optimal cut-off value differentiating responders from non-responders, with a sensitivity of $72.7 \%$ and specificity of $71.4 \%$ by ROC curve (Figure 1). Among $25(50 \%)$ patients classified as having $8 \mathrm{~W}-\mathrm{RDI} \geq 75 \%$, their 
best overall responses were PR, SD and PD in $68 \%, 24 \%$ and $8 \%$, respectively, while among $25(50 \%)$ patients classified as having $8 \mathrm{~W}$-RDI $<75 \%$, best responses were $20 \%, 32 \%$ and 48\%, respectively, (Figure 2A). Furthermore, PFS was significantly longer in patients with $8 \mathrm{~W}$-RDI of $\geq 75 \%$ compared to those with $8 \mathrm{~W}$-RDI $<75 \%$ [median $\mathrm{PFS}=7.4$ (95\% CI=5.9-9.8) vs. 3.3 (95\% CI=1.4-5.8) months, respectively; $p=0.004]$ (Figure 2B). The clinical characteristics of patients in whom $8 \mathrm{~W}$-RDI $\geq 75 \%$ was maintained are shown in Table III. Patients with 8W-RDI $\geq 75 \%$ were more likely to have a Child-Pugh score of 5 , ALBI grade of 1 , and presence of EHS by univariate analysis. All patients who started with a reduced dose were classified into the low 8W-RDI group.

AEs and DLTs. In this study, $42(84 \%)$ patients experienced DLTs: Drug interruption in 30 (60\%), dose reduction in 34 $(68 \%)$, and treatment withdrawal in nine $(18 \%)$ owing to intolerable side-effects. Thirty-two (64\%) patients developed DLTs during the first 8 weeks of treatment, and treatment withdrawal during the first 8 weeks caused by AEs was necessary in six (12\%) patients. Table IV shows incidence of individual AEs and AEs that caused DLTs during the initial 8 weeks. Regarding DLTs during the initial 8 weeks, fatigue was the most common reason $(\mathrm{n}=12,24 \%)$, followed by appetite loss $(\mathrm{n}=5,10 \%)$, reduced platelet count $(\mathrm{n}=5,10 \%)$ and proteinuria $(\mathrm{n}=5,10 \%)$; hypertension and hypothyroidism were uncommon among DLTs, despite their high frequency.

\section{Discussion}

Several prospective randomized trials on HCC (7-10) have demonstrated a significant correlation between OR evaluated by mRECIST and good prognosis. Thus, the importance of OR as a candidate surrogate endpoint of OS has been recognized $(8,23)$. Since no clear parameters exist for predicting the OR to lenvatinib therapy, the identification of such clinical parameters has become increasingly crucial. The present results demonstrated that $8 \mathrm{~W}$-RDI to be the only significant factor affecting OR in multivariate analysis (odds ratio $=1.036,95 \% \mathrm{CI}=1.001-1.072 ; p=0.041$ ), independent of standard clinical features. As far as we are aware, this is the first report to clarify the impact of RDI on treatment response in patients with $\mathrm{HCC}$ treated with lenvatinib.

In this retrospective study, 22 (44\%) patients achieved OR in the follow-up period. Among responders, 21 out of 22 patients $(95.5 \%)$ achieved OR at first evaluation after beginning lenvatinib therapy, and the other patient achieved OR at 24 weeks. The median time to response was 7.8 weeks, and the patient who achieved OR at 24 weeks had an $8 \mathrm{~W}-\mathrm{RDI}$ of $93 \%$. Thus, the definition of $8 \mathrm{~W}-\mathrm{RDI}$ as an early-phase indicator of the doses required for OR appears to be reasonable.

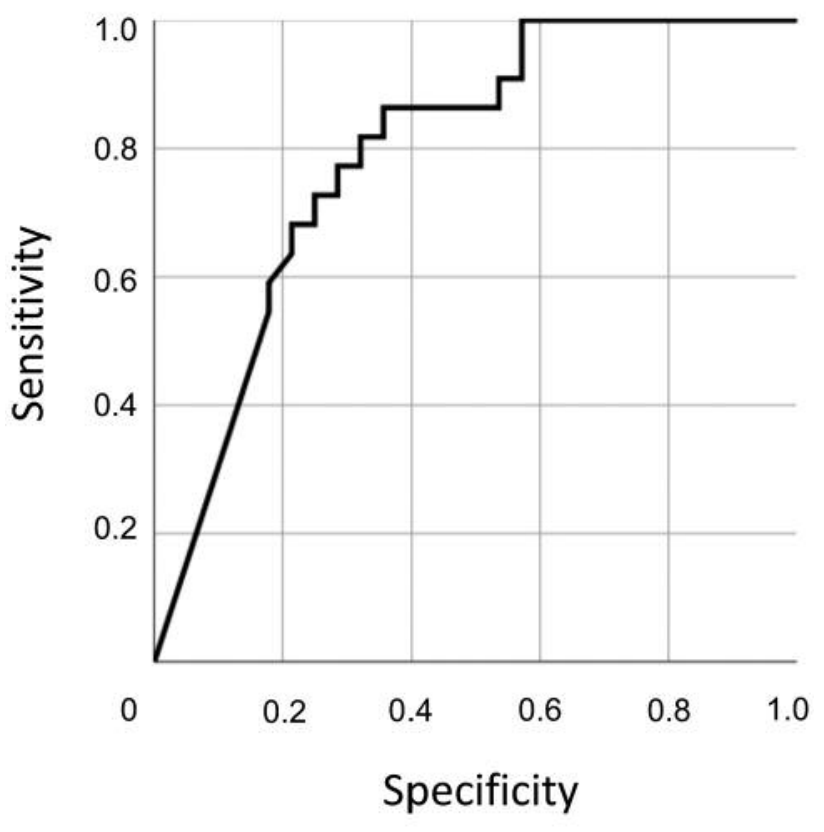

Figure 1. Receiver operating curves of the relative lenvatinib dose intensity 8 weeks after induction associated with objective response in patients with hepatocellular carcinoma treated with lenvatinib.

An $8 \mathrm{~W}-\mathrm{RDI}$ of $75 \%$ was determined to be the optimal cutoff value for differentiating responders from non-responders. At this cut-off value, the sensitivity and specificity were $72.7 \%$ and $71.4 \%$, respectively. The response rate in 25 (50\%) patients with $8 \mathrm{~W}-\mathrm{RDI} \geq 75 \%$ was greater $(68 \%$ vs. $20 \%$ ) and the PFS longer (7.4 vs. 3.3 months) compared with patients with $8 \mathrm{~W}-\mathrm{RDI}<75 \%$. For other cancer types treated with TKIs, RDI cut-off values ranging from $60 \%$ to $80 \%$ during the initial 3-12 weeks have been reported as predictive of longer PFS and OS (14-17). Our data concur with those cut-off values.

Our results suggest that lenvatinib may have dosedependent antitumor effects on HCC. A high RDI may have contributed to response because patients treated with a high RDI have a higher plasma concentration of lenvatinib than patients with low RDI. Hayato et al. reported that according to a pharmacokinetic/pharmacodynamic analysis, high relative doses of lenvatinib in simulations provided favorable clinical efficacy in patients with thyroid cancer (24). Additionally, several studies have revealed a correlation between higher plasma tyrosine kinase inhibitor concentration and better clinical outcomes in other types of cancer $(25,26)$. To our knowledge, this is the first report to identify an association between the actual dose delivered and treatment efficacy in patients with HCC treated with TKIs.

AE management is considered to be important for maintaining dose intensity. In the present study, fatigue was 
A

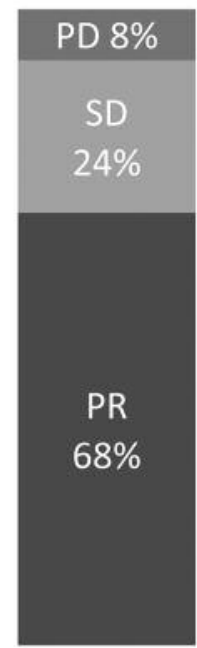

8 W-RDI $\geq 75 \%$
$(n=25)$

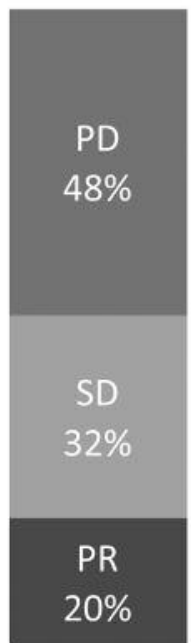

8 W-RDI $<75 \%$

$(n=25)$
B

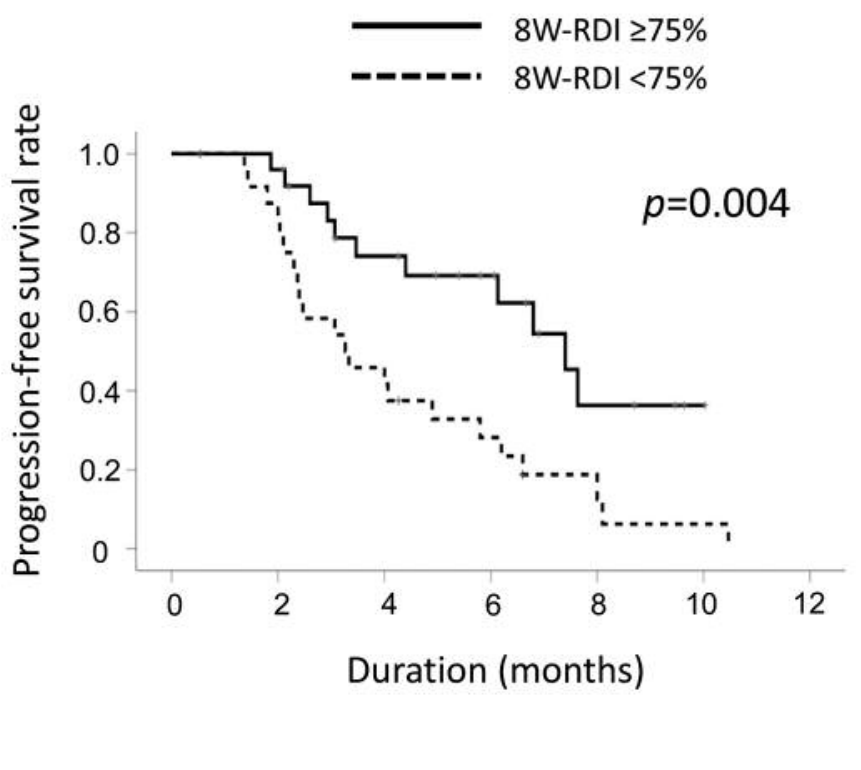

Figure 2. A: Frequency of best overall response to lenvatinib in patients with hepatocellular carcinoma according to relative lenvatinib dose intensity 8 weeks after induction ( $8 \mathrm{~W}-\mathrm{RDI})$ threshold. B: Cumulative progression-free survival rate according to $8 \mathrm{~W}$-RDI threshold. PD: Progressive disease; SD: stable disease; PR: partial response.

Table III. Patient characteristics according to relative dose intensity 8 weeks after lenvatinib induction ${ }^{\dagger}$.

\begin{tabular}{|c|c|c|c|c|}
\hline \multirow[b]{2}{*}{ Variable } & & \multicolumn{2}{|c|}{ 8W-RDI } & \multirow[b]{2}{*}{$p$-Value } \\
\hline & & $\geq 75 \%$ & $<75 \%$ & \\
\hline Age, years & Median (range) & $70(53-89)$ & $79(57-93)$ & 0.095 \\
\hline Sex, $\mathrm{n}$ & Male/female & $22 / 3$ & $16 / 9$ & 0.095 \\
\hline ECOG-PS, n & $0 / \geq 1$ & $18 / 7$ & $19 / 6$ & 1.000 \\
\hline Body weight, n & $<60 / \geq 60 \mathrm{~kg}$ & $19 / 6$ & $14 / 11$ & 0.232 \\
\hline Viral infection, $\mathrm{n}$ & Yes/no & $15 / 10$ & $12 / 13$ & 0.571 \\
\hline Child-Pugh score, $n$ & $5 / \geq 6$ & $21 / 4$ & $9 / 16$ & 0.001 \\
\hline ALBI, $\mathrm{n}$ & $1 / 2$ & $14 / 11$ & $4 / 21$ & 0.007 \\
\hline EHS, n & Yes/no & $11 / 14$ & $2 / 23$ & 0.008 \\
\hline MVI, n & Yes/no & $3 / 22$ & $5 / 20$ & 0.463 \\
\hline $\mathrm{AFP}, \mathrm{n}$ & $<90 / \geq 90 \mathrm{ng} / \mathrm{ml}$ & $16 / 9$ & $11 / 14$ & 0.256 \\
\hline PIVKA-II, n & $<540 / \geq 540 \mathrm{mAU} / \mathrm{ml}$ & $14 / 11$ & $12 / 13$ & 0.778 \\
\hline Initial dose of LEN, $n$ & Full/reduced & $25 / 0$ & $20 / 5$ & 0.022 \\
\hline
\end{tabular}

ECOG: Eastern Cooperative Oncology Group; PS: performance status; HBV: hepatitis B virus; HCV: hepatitis C virus; ALBI: albumin-bilirubin; EHS: extrahepatic spread; MVI: macrovascular invasion; AFP: alpha-fetoprotein; PIVKA-II: protein induced by vitamin K absence or antagonistII; TACE: transarterial chemoembolization; LEN: lenvatinib; 8 W-RDI: relative dose intensity 8 weeks after lenvatinib induction. Bold font indicates significant $p$-values.

by far the most common DLT during the first 8 weeks, followed by appetite loss, reduced platelet count, and proteinuria. Prophylactic use of dexamethasone has been proposed to be effective in reducing fatigue during regorafenib treatment in patients with metastatic colorectal cancer, thereby prolonging the time to regorafenib dose modification $(27,28)$. The beneficial effects of the herbal drug Bojungikki-tang (Chinese; Hochu-ekki-to in Japanese) 
Table IV. Adverse events (AEs) and dose-limiting toxicities (DLTS) during the initial 8 weeks of lenvatinib therapy in patients with hepatocellular carcinoma.

\begin{tabular}{lccc}
\hline Adverse event & Total* & \multicolumn{2}{c}{$\begin{array}{c}\text { DLTs during initial } \\
8 \text { weeks, n }(\%)\end{array}$} \\
\cline { 3 - 4 } & & $\begin{array}{c}8 \text { W-RDI } \\
\geq 75 \%\end{array}$ & $\begin{array}{c}8 \text { W-RDI } \\
<75 \%\end{array}$ \\
\hline Fatigue & & $3(6 \%)$ & $9(18 \%)$ \\
Hypertension & $25(50 \%)$ & 0 & $1(2 \%)$ \\
Diarrhea & $36(72 \%)$ & 0 & $3(6 \%)$ \\
Appetite loss & $10(20 \%)$ & 0 & $4(8 \%)$ \\
Nausea & $13(26 \%)$ & $1(2 \%)$ & $3(6 \%)$ \\
Hand-foot skin reaction & $6(12 \%)$ & 0 & $1(2 \%)$ \\
Decreased platelets & $26(52 \%)$ & $2(4 \%)$ & $4(8 \%)$ \\
Proteinuria & $8(16 \%)$ & $1(2 \%)$ & $3(6 \%)$ \\
Hypothyroidism & $25(50 \%)$ & $2(4 \%)$ & 0 \\
Decreased liver function & $30(60 \%)$ & 0 & $2(4 \%)$ \\
Hepatic encephalopathy & $11(22 \%)$ & $1(2 \%)$ & $3(6 \%)$ \\
Rupture of esophageal varices & $2(8 \%)$ & 0 & $2(4 \%)$ \\
\hline
\end{tabular}

*Evaluated according to the National Cancer Institute's Common Terminology Criteria for Adverse Events, version 4.0 (21).

in the management of cancer-related fatigue have also been reported (29). In order to clarify whether such supportive care might help maintain a high RDI for patients with HCC, further prospective studies are needed.

The $8 \mathrm{~W}$-RDI was also affected by the characteristics of patients before treatment. The present results revealed a Child-Pugh score of 5, ALBI grade of 1, and presence of EHS as significant factors in univariate analysis for high $8 \mathrm{~W}-$ RDI. The relationship between Child-Pugh score of $5 / 6$ or ALBI grade of $1 / 2$ and dose modification due to lenvatinibinduced toxicity has not been clarified. However, it has been reported that DLTs are more likely to occur in patients with HCC with Child-Pugh score of B than those with a score of A (30). Since lenvatinib is primarily metabolized by cytochrome P450 3A4 (31), hepatic dysfunction may lead to increased lenvatinib exposure (32) and a consequent decrease in RDI. The impact of reduced liver function also explains why it was possible to maintain a high RDI in patients with EHS. The ALBI grade of patients with EHS was significantly better than that of those without $(p=0.03)$ (data not shown). Further studies are required to determine the association between RDI and liver function and HCC profile in patients treated with lenvatinib.

This study has several limitations. It was a retrospective multi-center study with a small patient cohort. The findings were affected by unavoidable biases in patient selection. Since we were unable to investigate the associations between $8 \mathrm{~W}-\mathrm{RDI}$ and OS due to the short follow-up period, whether the $8 \mathrm{~W}$-RDI of lenvatinib affects long-term disease control in patients with HCC remains unclear. Further studies to validate the present data in a large cohort and identify pretreatment risk factors for reduced RDI are needed.

In conclusion, we have identified a clear goal during earlyphase treatment of HCC with lenvatinib. The present results suggest that maintaining a high dose intensity of lenvatinib during at least the initial 8 weeks of treatment may enable better responses among patients with HCC. This evidencebased therapeutic target will not only help clinicians select the most appropriate therapy from among several options, but also encourage both clinicians and patients to maintain their motivation in favor of HCC treatment.

\section{Conflicts of Interest}

Yoshito Itoh received lecture fees from the Bristol-Myers Squibb Company and Merck Sharp and Dohme and commercial research funding from Bayer AG, Eisai Co., Ltd., Bristol-Myers Squibb Company, and Merck Sharp and Dohme. Michihisa Moriguchi received lecture fees from Bayer AG and Eisai Co., Ltd.

\section{Authors' Contributions}

Conception and design: A.T., M.M., Y.S. Provision of study materials or patients: A.T., M.M., Y.S., H.I., T.Y., H.K., H.F., T.S., Y.M., H.I, H.T., Y.N., M.J., M.A., T.H., A.O., A.M., A.M., N.Y., T.N., H.M., A.U., T.N., K.Y., Y.I. Collection and assembly of data: A.T., M.M., Y.S. Data analysis and interpretation: all Authors. Article writing: all Authors. Final approval of article: all Authors.

\section{Acknowledgements}

The Authors thank all the investigators of this study.

\section{References}

1 Torre LA, Bray F, Siegel RL, Ferlay J, Lortet-Tieulent J and Jemal A: Global cancer statistics, 2012. CA Cancer J Clin 65: 87-108, 2015. PMID: 25651787. DOI: 10.3322/caac.21262

2 Heimbach JK, Kulik LM, Finn RS, Sirlin CB, Abecassis MM, Roberts LR, Zhu AX, Murad MH and Marrero JA: AASLD guidelines for the treatment of hepatocellular carcinoma. Hepatology 67: 358-380, 2018. PMID: 28130846. DOI: 10.1002/ hep. 29086

3 EASL Clinical Practice Guidelines: Management of hepatocellular carcinoma. J Hepatol 69: 182-236, 2018. PMID: 29628281. DOI: 10.1016/j.jhep.2018.03.019

4 Bupathi M, Kaseb A, Meric-Bernstam F and Naing A: Hepatocellular carcinoma: Where there is unmet need. Mol Oncol 9: 1501-1509, 2015. PMID: 26160430. DOI: 10.1016/ j.molonc.2015.06.005

5 Kudo M, Finn RS, Qin S, Han KH, Ikeda K, Piscaglia F, Baron A, Park JW, Han G, Jassem J, Blanc JF, Vogel A, Komov D, Evans TRJ, Lopez C, Dutcus C, Guo M, Saito K, Kraljevic S, Tamai T, Ren $M$ and Cheng AL: Lenvatinib versus sorafenib in first-line treatment of patients with unresectable hepatocellular carcinoma: a randomised phase 3 non-inferiority trial. Lancet 391: 1163-1173, 2018. PMID: 29433850. DOI: 10.1016/S0140-6736(18)30207-1 
6 Lencioni R and Llovet JM: Modified RECIST (mRECIST) assessment for hepatocellular carcinoma. Semin Liver Dis 30: 52-60, 2010. PMID: 20175033. DOI: $10.1055 / \mathrm{s}-0030-1247132$

7 Kudo M, Finn RS, Qin S, Han KH, Ikeda K, Cheng AL, Piscaglia F, Ueshima K, Aikata H, Vogel A, Lopez C, Pracht M, Meng Z, Daniele B, Park JW, Palmer DH, Dutcus CE, Tamai T, Saito K and Lencioni R: Analysis of survival and objective response (OR) in patients with hepatocellular carcinoma in a phase III study of lenvatinib (REFLECT). J Clin Oncol 37(4 suppl): abstract 186, 2019. DOI: $10.1200 / J C O .2019 .37 .4 \_s u p p l .186$

8 Lencioni R, Montal R, Torres F, Park JW, Decaens T, Raoul JL, Kudo M, Chang C, Ríos J, Boige V, Assenat E, Kang YK, Lim HY, Walters I and Llovet JM: Objective response by mRECIST as a predictor and potential surrogate end-point of overall survival in advanced HCC. J Hepatol 66: 1166-1172, 2017. PMID: 28131794. DOI: 10.1016/j.jhep.2017.01.012

9 Meyer T, Palmer DH, Cheng AL, Hocke J, Loembé AB and Yen CJ: mRECIST to predict survival in advanced hepatocellular carcinoma: Analysis of two randomised phase II trials comparing nintedanib vs. sorafenib. Liver Int 37: 1047-1055, 2017. PMID: 28066978. DOI: 10.1111/liv.13359

10 Kudo M, Ueshima K, Yokosuka O, Ogasawara S, Obi S, Izumi N, Aikata H, Nagano H, Hatano E, Sasaki Y, Hino K, Kumada T, Yamamoto K, Imai Y, Iwadou S, Ogawa C, Okusaka T, Kanai F, Akazawa K, Yoshimura KI, Johnson P, Arai Y and SILIUS study group: Sorafenib plus low-dose cisplatin and fluorouracil hepatic arterial infusion chemotherapy versus sorafenib alone in patients with advanced hepatocellular carcinoma (SILIUS): A randomised, open label, phase 3 trial. Lancet Gastroenterol Hepatol 3: 424-432, 2018. PMID: 29631810. DOI: 10.1016/S24 68-1253(18)30078-5

11 Yoshimoto T, Imura S, Morine Y, Ikemoto T, Arakawa Y, Iwahashi S, Saito YU, Takasu C, Ishikawa D, Teraoku H, Bando $\mathrm{Y}$ and Shimada M: The outcome of sorafenib therapy on unresectable hepatocellular carcinoma: Experience of conversion and salvage hepatectomy. Anticancer Res 38: 501-507, 2018. PMID: 29277815. DOI: 10.21873/anticanres.12250

12 Lu LC, Shao YY, Chan SY, Hsu CH and Cheng AL: Clinical characteristics of advanced hepatocellular carcinoma patients with prolonged survival in the era of anti-angiogenic targetedtherapy. Anticancer Res 34: 1047-1052, 2014. PMID: 24511053.

13 Havrilesky LJ, Reiner M, Morrow PK, Watson H and Crawford $\mathrm{J}$ : A review of relative dose intensity and survival in patients with metastatic solid tumors. Crit Rev Oncol Hematol 93: 203210, 2015. PMID: 25459671. DOI: 10.1016/j.critrevonc. 2014.10.006

14 Ishihara H, Takagi T, Kondo T, Iwamoto K, Tachibana H, Yoshida K, Omae K, Iizuka J, Kobayashi $\mathrm{H}$ and Tanabe $\mathrm{K}$ : Decreased relative dose intensity during the early phase of treatment impacts the therapeutic efficacy of sunitinib in metastatic renal cell carcinoma. Jpn J Clin Oncol 48: 667-672, 2018. PMID: 29860353. DOI: 10.1093/jjco/hyy078

15 Komatsu Y, Ohki E, Ueno N, Yoshida A, Toyoshima Y, Ueda E, Houzawa H, Togo K and Nishida T: Safety, efficacy and prognostic analyses of sunitinib in the post-marketing surveillance study of Japanese patients with gastrointestinal stromal tumor. Jpn J Clin Oncol 45: 1016-1022, 2015. PMID: 26373318. DOI: $10.1093 /$ jjco/hyv126

16 Nakano K, Funauchi Y, Hayakawa K, Tanizawa T, Ae K, Matsumoto $\mathrm{S}$ and Takahashi S: Relative dose intensity of induction-phase pazopanib treatment of soft tissue sarcoma: Its relationship with prognoses of pazopanib responders. J Clin Med 8: 8, 2019. PMID: 30626115. DOI: 10.3390/jcm8010060

17 Hughes TP, Branford S, White DL, Reynolds J, Koelmeyer R, Seymour JF, Taylor K, Arthur C, Schwarer A, Morton J, Cooney J, Leahy MF, Rowlings P, Catalano J, Hertzberg M, Filshie R, Mills AK, Fay K, Durrant S, Januszewicz H, Joske D, Underhill C, Dunkley S, Lynch K, Grigg A and Australasian Leukaemia and Lymphoma Group: Impact of early dose intensity on cytogenetic and molecular responses in chronic- phase CML patients receiving $600 \mathrm{mg} /$ day of imatinib as initial therapy. Blood 112: 3965-3973, 2008. PMID: 18768781. DOI: 10.1182/ blood-2008-06-161737

18 Hiraoka A, Kumada T, Kariyama K, Takaguchi K, Itobayashi E, Shimada N, Tajiri K, Tsuji K, Ishikawa T, Ochi H, Hirooka M, Tsutsui A, Shibata H, Tada T, Toyoda H, Nouso K, Joko K, Hiasa Y, Michitaka K and Real-life Practice Experts for HCC (RELPEC) Study Group and the HCC 48 Group (hepatocellular carcinoma experts from 48 clinics in Japan): Therapeutic potential of lenvatinib for unresectable hepatocellular carcinoma in clinical practice: Multicenter analysis. Hepatol Res 49: 111117, 2019. PMID: 30144256. DOI: 10.1111/hepr.13243

19 Hiraoka A, Kumada T, Kariyama K, Takaguchi K, Atsukawa M, Itobayashi E, Tsuji K, Tajiri K, Hirooka M, Shimada N, Shibata H, Ishikawa T, Ochi H, Tada T, Toyoda H, Nouso K, Tsutsui A, Itokawa N, Imai M, Joko K, Hiasa Y, Michitaka K and Real-life Practice Experts for HCC (RELPEC) Study Group, HCC 48 Group (hepatocellular carcinoma experts from 48 clinics in Japan): Clinical features of lenvatinib for unresectable hepatocellular carcinoma in real-world conditions: Multicenter analysis. Cancer Med 8: 137-146, 2019. PMID: 30575325. DOI: 10.1002/cam4.1909

20 Marrero JA, Kulik LM, Sirlin CB, Zhu AX, Finn RS, Abecassis MM, Roberts LR and Heimbach JK: Diagnosis, Staging, and Management of Hepatocellular Carcinoma: 2018 Practice Guidance by the American Association for the Study of Liver Diseases. Hepatology 68(2): 723-750. PMID: 29624699. DOI: 10.1002/hep.29913

21 National Cancer Institute, Protocol Development Cancer Therapy. Available at: https://ctep.cancer.gov/protocol Development/ electronic_applications/ctc.htm-ctc_40 (Accessed May 31, 2018)

22 Johnson PJ, Berhane S, Kagebayashi C, Satomura S, Teng M, Reeves HL, O'Beirne J, Fox R, Skowronska A, Palmer D, Yeo W, Mo F, Lai P, Iñarrairaegui M, Chan SL, Sangro B, Miksad R, Tada T, Kumada T and Toyoda H: Assessment of liver function in patients with hepatocellular carcinoma: a new evidence-based approach-the ALBI grade. J Clin Oncol 33: 550-558, 2015. PMID: 25512453. DOI: 10.1200/JCO.2014.57.9151

23 Llovet JM, Montal R and Villanueva A: Randomized trials and endpoints in advanced HCC: Role of PFS as a surrogate of survival. J Hepatol 70: 1262-1277, 2019. PMID: 30943423. DOI: $10.1016 /$ j.jhep.2019.01.028

24 Hayato S, Shumaker R, Ferry J, Binder T, Dutcus CE and Hussein Z: Exposure-response analysis and simulation of lenvatinib safety and efficacy in patients with radioiodinerefractory differentiated thyroid cancer. Cancer Chemother Pharmacol 82: 971-978, 2018. PMID: 30244318. DOI: 10.1007/ s00280-018-3687-4

25 Houk BE, Bello CL, Poland B, Rosen LS, Demetri GD and Motzer RJ: Relationship between exposure to sunitinib and efficacy and tolerability endpoints in patients with cancer: 
Results of a pharmacokinetic/pharmacodynamic meta-analysis. Cancer Chemother Pharmacol 66: 357-371, 2010. PMID: 19967539. DOI: 10.1007/s00280-009-1170-y

26 Li C, Wang B, Chen SC, Wada R, Lu D, Wang X, Polhamus D, French J, Vadhavkar S, Strasak A, Smitt M, Joshi A, Samant M, Quartino A, Jin J and Girish S: Exposure-response analyses of trastuzumab emtansine in patients with HER2-positive advanced breast cancer previously treated with trastuzumab and a taxane. Cancer Chemother Pharmacol 80: 1079-1090, 2017. PMID: 29022084. DOI: $10.1007 / \mathrm{s} 00280-017-3440-4$

27 Tanioka H, Miyamoto Y, Tsuji A, Asayama M, Shiraishi T, Yuki S, Kotaka M, Makiyama A, Shimokawa M, Shimose T, Masuda S, Yamaguchi T, Komatsu Y, Saeki H, Emi Y, Baba , Oki E, Maehara Y and Kyushu Study Group of Clinical Cancer (KSCC): Prophylactic effect of dexamethasone on regorafenibrelated fatigue and/or malaise: A randomized, placebocontrolled, double-blind clinical study in patients with unresectable metastatic colorectal cancer (KSCC1402/HGCSG 1402). Oncology 94: 289-296, 2018. PMID: 29514163. DOI: $10.1159 / 000486624$

28 Fukuoka S, Shitara K, Noguchi M, Kawazoe A, Kuboki Y, Bando H, Okamoto W, Kojima T, Doi T, Ohtsu A and Yoshino T: Prophylactic use of oral dexamethasone to alleviate fatigue during regorafenib treatment for patients with metastatic colorectal cancer. Clin Colorectal Cancer 16: e39-e44, 2017. PMID: 27780748. DOI: 10.1016/j.clcc.2016.07.012
29 Jeong JS, Ryu BH, Kim JS, Park JW, Choi WC and Yoon SW: Bojungikki-tang for cancer-related fatigue: a pilot randomized clinical trial. Integr Cancer Ther 9: 331-338, 2010. PMID: 21059621. DOI: $10.1177 / 1534735410383170$

30 Ikeda M, Okusaka T, Mitsunaga S, Ueno H, Tamai T, Suzuki T, Hayato S, Kadowaki T, Okita K and Kumada H: Safety and pharmacokinetics of lenvatinib in patients with advanced hepatocellular carcinoma. Clin Cancer Res 22: 1385-1394, 2016. PMID: 26500236. DOI: 10.1158/1078-0432.CCR-15-1354

31 Dubbelman AC, Rosing H, Nijenhuis C, Huitema AD, MerguiRoelvink M, Gupta A, Verbel D, Thompson G, Shumaker R, Schellens JH and Beijnen JH: Pharmacokinetics and excretion of (14)C-lenvatinib in patients with advanced solid tumors or lymphomas. Invest New Drugs 33: 233-240, 2015. PMID: 25377392. DOI: $10.1007 / \mathrm{s} 10637-014-0181-7$

32 Shumaker R, Aluri J, Fan J, Martinez G, Pentikis H and Ren M: Influence of hepatic impairment on lenvatinib pharmacokinetics following single-dose oral administration. J Clin Pharmacol 55: 317-327, 2015. PMID: 25204557. DOI: 10.1002/jcph.398

Received July 4, 2019

Revised July 13, 2019

Accepted July 16, 2019 